\title{
Kulturversuche mit Aspergillus niger auf einigen Aminosăuren und Peptiden.
}

\author{
Von \\ Emil Abderhalden und Yutaka Terunchi. \\ (Aus dem I. chemischen Institute der Universität Berlin.) \\ (Der Redaktion zugegangen am 11. März 1906.)
}

Daß die meisten $\alpha$-Aminosäuren ein gutes Nährmaterial für Pilze darstellen, ist bekannt. 0. Emmerling ${ }^{1}$ ) hat außerdem nachgewiesen, daß in der Nährflüssigkeit als Abbauprodukt derselben oxalsaures Ammon auftritt. Uns interessierte die Frage, ob die verschiedenartigen synthetischen Polypeptide in gleicher Weise von Aspergillus niger als Nahrung benutzt werden, wie die Aminosäuren, und ob sich in bezug auf das Wachstum bei verschiedenen Peptiden Unterschiede zeigen. Als Nährlösung verwandten wir: $1000 \mathrm{~g}$ destilliertes Wasser, $0,5 \mathrm{~g}$ Magnesiumsulfat, 1,0 g Kaliumphosphat, 0,5 g Kaliumchlorid, 0,01 g Ferrosulfat und $3 \%$ Rohrzucker. In einem Teil der Versuche wurde der Zuckerzusatz weggelassen.

$\mathrm{Zu}$ den einzelnen Versuchen verwandten wir je $25 \mathrm{ccm}$ der genannten Lösung. Jede Probe wurde nach Zusatz der betreffenden Aminosäure resp. des Polypeptides im Dampftopf sterilisiert und dann mit Aspergillussporen geimpft. Nach siebentägigem Verweilen im Brutraum wurde die Pilzmasse auf einem gewogenen Filter gesammelt, bei $100^{\circ}$ getrocknet, und dann das Gewicht bestimmt. Die abfiltrierte Flüssigkeit prüften wir auf Oxalsäure. Wie die untenstehende Tabelle zeigt, ließen sich wohl Unterschiede im Wachstum auf verschiedenen Aminosäuren und Peptiden feststellen. Als sehr geeignet erwiesen sich Gly-

1) 0. Emmerling, Oxalsäurebildung durch Schimmelpilze. Zentralbl. für Bakteriol., Parasitenkunde und Infektionskrankheiten. Bd. X, S. 273, 1903. 
Kulturversuche mit Aspergillus niger auf einigen Aminosăuren usw.

kokoll, Glycyl-glycin und Triglycin. Auch auf Glycinanhydrid wuchs Aspergillus niger ganz gut und ebenso auf den entsprechenden Alaninverbindungen.

\begin{tabular}{|c|c|c|c|c|c|c|c|}
\hline \multirow{2}{*}{$\begin{array}{l}\text { Zugesetzte Aminosäurem } \\
\text { resp. Peptide in Grammen } \\
=0,05 \mathrm{~g} \text { Stickstoff }\end{array}$} & & \multicolumn{2}{|c|}{$\begin{array}{r}\text { Versuch I } \\
\text { ohne Ro }\end{array}$} & \multicolumn{2}{|c|}{$\begin{array}{l}\text { Versuch II } \\
\text { arzucker }\end{array}$} & \multicolumn{2}{|c|}{$\begin{array}{c}\text { Versuch III } \\
\text { mit } \\
\text { Rohrzucker }\end{array}$} \\
\hline & & $\begin{array}{l}\text { Pilz } \\
\text { in } \\
\text { mg }\end{array}$ & $\begin{array}{l}\text { Nach- } \\
\text { weis*) } \\
\text { der } \\
\text { Oxal- } \\
\text { säure }\end{array}$ & $\begin{array}{c}\text { Pilz } \\
\text { in } \\
\mathrm{mg}\end{array}$ & $\begin{array}{l}\text { Nach- } \\
\text { weis } \\
\text { der } \\
\text { Oxal- } \\
\text { säure }\end{array}$ & $\begin{array}{c}\text { Pilz } \\
\text { in } \\
\mathrm{mg}\end{array}$ & $\begin{array}{c}\text { Nach } \\
\text { weis } \\
\text { der } \\
\text { Oxal } \\
\text { säure }\end{array}$ \\
\hline Glykokoll . . . . . . & 0,27 & 15 & ++ & & & 231 & $+t$ \\
\hline Glycyl-glycin & 0,24 & 15 & ++ & & & 254 & + \\
\hline Diglycyl-glycin . . . • & 0,23 & 17 & ++ & & & 228 & + \\
\hline 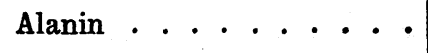 & 0,32 & 18 & ++ & & & 209 & $\stackrel{+}{++}$ \\
\hline Alanyl-alanin . . . . & 0,29 & 10 & - & 10 & - & 202 & $\stackrel{+}{++}$ \\
\hline Glycinanhydrid . . . . & 0,21 & 16 & + & 17 & + & 244 & - \\
\hline Alaninanhydrid . . . . & 0,26 & 13 & + & 27 & ++ & 246 & - \\
\hline Leucyl-glycin . . . • & 0,24 & 21 & ++ & 19 & $+t$ & 159 & $\stackrel{+}{++}$ \\
\hline Glycyl-alanin & 0,25 & 12 & - & 20 & ++ & 167 & - \\
\hline Leucyl-glycyl-glycin . . • & 0,29 & 11 & - & & & 192 & + \\
\hline Leucylasparagin . . • & 0,34 & 20 & ++ & & & 224 & ++ \\
\hline $\begin{array}{l}\text { Aminobutyryl-aminobutter- } \\
\text { säure A } \ldots . .\end{array}$ & 0,29 & 10 & - & & & 208 & \\
\hline
\end{tabular}

*) - bedeutet negativ, + Spur, ++ deutlich, ++ sehr viel.

Glycyl-alanin, Leucyl-glycyl-glycin, Aminobuttyryl-aminobuttersäure A scheinen am wenigsten geeignet gewesen zu sein. Die Menge der gebildeten Oxalsäure erwies sich im allgemeinen als der gewachsenen Masse an Pilzrasen entsprechend. Wir haben sie nicht genau bestimmt, sondern uns mit der rohen Beobachtung begnügt, weil wir vorläufig zu wenig über die Entstehung des oxalsauren Ammons und vor allem über seine Beziehung zu dem Wachstum des Pilzes und dessen Stoffwechsel wissen. Es ist wohl möglich, daß es fortwährend weiter Verwendung findet, und die Menge des gebildeten oxal- 
396 Abderhalden u. Teruuchi, Kulturversuche mit Aspergilis niget.

sauren Ammons durchaus kein Maß der Wachstumsirensität des Pilzes ist. Am besten würde man seine Menge whl mit der gebildeten Stickstoffsubstanz des Pilzes in Beziehung ringen. Die Wägung der Pilze vermag uns auch kein genaues Bd über die Stickstoffassimilation aus den beigegebenen Aminosäuen und Peptiden zu geben. Der verschiedene Salzgehalt kannbei so kleinen Pilzmengen die Vergleichung sehr stören. Auh hier wäre es korrekter, die gebildeten Stickstoffsubstanzen i Rechnung zu setzen. Bei so kleinen Pilzmengen waren drartige Bestimmungen ausgeschlossen. Wir hoffen, diese Versche in der angedeuteten Richtung bald weiterführen zu könne. 